\title{
Test Results for Entry Guidance Methods for Space Vehicles
}

\author{
John M. Hanson* \\ NASA Marshall Space Flight Center, Huntsville, AL 35812 \\ Robert E. Jones ${ }^{\dagger}$ \\ Sverdrup Technology, Inc., Huntsville, AL 35806
}

\begin{abstract}
There are a number of approaches to advanced guidance and control that have the potential for achieving the goals of significantly increasing reusable launch vehicle (or any space vehicle that enters an atmosphere) safety and reliability, and reducing the cost. This paper examines some approaches to entry guidance. An effort called Integration and Testing of Advanced Guidance and Control Technologies has recently completed a rigorous testing phase where these algorithms faced high-fidelity vehicle models and were required to perform a variety of representative tests. The algorithm developers spent substantial effort improving the algorithm performance in the testing. This paper lists the test cases used to demonstrate that the desired results are achieved, shows an automated test scoring method that greatly reduces the evaluation effort required, and displays results of the tests. Results show a significant improvement over previous guidance approaches. The two best-scoring algorithm approaches show roughly equivalent results and are ready to be applied to future vehicle concepts.
\end{abstract}

\footnotetext{
* Team Lead, Guidance, Navigation, and Control Group, TD54, Marshall Space Flight Center,
} AL 35812, Member AIAA

† Senior Engineer, 6703 Odyssey Drive NW, Suite 303, Huntsville, AL 35806 


\section{INTRODUCTION}

Advanced guidance and control has a significant potential to increase the safety of future reusable launch vehicles (RLV) and any space vehicles, as well as to reduce the cost of performing guidance and control analysis, both in the design and in the operational phases. It also has potential (reduced) benefit to expendable vehicles. This potential has been documented elsewhere ${ }^{1,2}$. The improvement in safety results from the ability to adapt to unexpected significant off-nominal conditions and failure scenarios. The improvement in cost results from the ability to use the methods for varying vehicle models and mission scenarios without significant effort expended.

The Advanced Guidance and Control Project, which was supported by the NASA X-33 Program Office, had as its purpose to develop and test some of the potential methods. The testing was performed in a high-fidelity simulation, against a number of stressing conditions, in order to discern the most flexible approaches. This effort was subsequently funded under the Space Launch Initiative, and later by the Next Generation Launch Technologies Program under the name Integration and Testing of Advanced Guidance and Control Technologies (ITAGCT).

This paper describes some advanced approaches for entry guidance. We summarize an initial phase of testing performed to examine the various methods. Some lessons were learned from the initial phase of testing. Some of the algorithms performed well, but for the most part the methods were not ready to address all the RLV needs. A second phase of testing was planned to 
more completely examine the performance of the algorithms versus the safety and cost requirements. This paper includes a description of the test cases for the second phase of testing. We also describe an automated method of scoring the algorithm performance that leads to a significant reduction of effort. Results are shown at the end of the paper. We also examine computational effort expended by the algorithms. This paper is the first in what is hoped to be a series of papers that examines tests of the various algorithms needed for a complete advanced guidance and control architecture. A complete architecture will include all phases of flight, with advanced guidance, control, and control allocation all included, as well as an automated mission manager to oversee the decision-making for the guidance and control, and potentially a system identification module to identify how the behavior of the vehicle is different from the expected behavior.

\section{FIRST PHASE OF TESTING}

An original goal in this effort was to include as many approaches as possible within the resources of the effort, with an eye toward not missing what may be the best approach. The methods had to be openly available (not proprietary), and available with a relatively small budget. This led to an emphasis on university grants and in-house efforts.

A test series was conducted in September 2000. Four entry guidance methods were tested. The test environment was the X-33 Marshall Aerospace Vehicle Representation in C (MAVERIC) simulation $^{3}$. MAVERIC was the only high-fidelity end-to-end simulation used for X-33 design. Its results impacted structural, thermal, and control system design. It was used to develop the 
ascent and entry guidance and control, as well as the flight mechanics portion of the mission manager. At the end of the X-33 Program, MAVERIC was matching the Integrated Test Facility simulation that was to be used for verification of the flight software, in its all-digital mode.

The X-33 was planned to fly a number of sub-orbital test flights, so these tests encompassed primarily ascent followed immediately by entry on sub-orbital trajectories. The sub-orbital flights can be viewed as representing different downrange aborts for a RLV. These tests are particularly stressing for entry guidance, because the duration of the entry phase is short, and because the entry guidance has to remove dispersions that result from the ascent phase. Additional tests were run for entry from various orbits, using the same simulation and vehicle models, with differing crossrange requirements and heat constraints.

Tests during Phase 1 included different nominal missions, engine-out aborts, Monte Carlo dispersion runs for both nominal missions and aborts, and significant engine over and under performance. Failures and mis-modeling not associated with the propulsion system were not explicitly considered for this Phase 1 testing. Algorithm size, speed of execution, memory, complexity/effort required, and performance against a variety of criteria were all compared.

Of all the methods tested, the linear quadratic regulator (LQR) entry guidance was the only one that performed quite well. In all cases (including LQR), it became clear that more work was necessary to develop the algorithms to their full potential, so that they would successfully fly the various test cases. This led to the definition of a second set of tests, as described below, and to more work on the algorithms, as described in the references. The manual examination of results 
performed during the Phase 1 testing led to an automated test procedure for Phase 2, as described below.

\section{METHODS TO BE EXAMINED}

The work in this paper continues from work first described in References 3 and 4 . The following describes the different methods involved in this integration and testing.

- Baseline guidance ${ }^{5}$. This method is like the Shuttle entry guidance in that it tracks a nominal drag versus energy profile for longitudinal guidance and uses a heading error corridor to trigger periodic bank sign reversals for lateral guidance. It was the baseline entry guidance for X-33. The drag profile is stored as a piecewise linear function of energy. The nominal range to go calculation is a simple table lookup. Feedback linearization is used to define a tracking law for the drag profile. A damped harmonic oscillator model defines the desired time response, which is used to tune the guidance. Biasing of the Terminal Area Energy Management (TAEM) target and adjustment of the desired drag profile compensate for dispersions and cause the actual range to approximate the range that is obtained from flying the drag profile. TAEM is the flight phase that occurs after entry and is focused on setting up the landing phase. For this study, the TAEM interface is at about $762 \mathrm{~m} / \mathrm{s}(2500 \mathrm{fps})$ relative speed, $55.56 \mathrm{~km}(30 \mathrm{~nm})$ from the landing area, and at about $29 \mathrm{~km}(95,000 \mathrm{ft})$ altitude. Bank angle is the primary control, but modulation of angle of attack (within 5 degrees of the nominal profile) is used, especially during bank reversals, to help with transient behavior. This guidance was used for a portion of the tests, for comparison purposes. It was not used 
for the complete set of tests because of the time it would have taken to set it up and tune it properly for all tests.

- Linear quadratic regulator $(L Q R)$. This method ${ }^{6}$ has performed very well in test. The algorithm is of the reference profile tracking type. The reference profile consists of reference states: range to go, altitude, and flight path angle; and reference controls: bank angle and angle of attack, versus energy. A linear control law using state feedback is used with energyscheduled gains. The gains are obtained offline using Matlab's steady state linear quadratic regulator function. Lateral trajectory control is obtained through bank sign reversals chosen based on a heading error corridor. The algorithm is not quite as flexible as methods with onboard trajectory re-generation capability, but it is very robust with respect to varying initial conditions. The guidance gains are for the most part trajectory-independent.

- Predictor-corrector. This method ${ }^{7}$, called Eguide, chooses parameters using a Newton procedure and numerical integration to obtain a desirable trajectory on-board for the actual flight conditions. Eguide follows a reference heat rate early in entry. A total of four parameters are chosen for entry: reference heat rate, initial bank angle, bank angle rate, and the time to switch from heat rate tracking to targeting the TAEM interface. After the high heating region is passed, Eguide uses initial bank and bank rate to target the TAEM interface. EGuide contains a planning stage and also functions as guidance with a combination of a predictor/corrector and a profile-follower using the LQR guidance just described. This method results in very smooth bank angle and angle of attack commands, and a smooth altitude profile. A bank reversal is chosen to satisfy the lateral motion necessary to reach the TAEM interface. 
- A trajectory design method that uses quasi-equilibrium glide (shallow and nearly constant flight path angle with varying bank angle), combined with a predictor-corrector method, to design a trajectory for entry ${ }^{8}$. The use of equilibrium glide during the high heating portion of entry enables the inequality constraints to be observed. The entry trajectory design problem is decomposed into two sequential one-parameter search problems. The 3-dimensional trajectory is derived (longitudinal and lateral motion), to ensure that the TAEM interface will be successfully reached. First, the motion for the initial entry into the atmosphere and the longitudinal profile for the pre-TAEM portion are found. Next, the method estimates the longitudinal profile for the high-heating quasi-equilibrium glide phase. Integrating the equations of motion enables the trajectory to converge and to follow the correct vehicle dynamics. The combined longitudinal motion satisfies the constraints and end conditions. A bank reversal is chosen to satisfy the lateral motion requirements. A profile-following guidance flies the trajectory, focusing on following all the trajectory parameters ${ }^{9}$.

- An entry trajectory design and guidance procedure based on extension of the Shuttle trajectory design methods to three dimensions ${ }^{10}$. The method is called EAGLE, for Evolved Acceleration Guidance Logic for Entry. The planning algorithm generates reference drag acceleration and lateral acceleration profiles, along with the reference state and bank angle profiles. EAGLE chooses a drag profile using a 3-segment linear spline fit for a profile that fits within the drag versus velocity constraints and gives the correct value for downrange distance. These constraints can include thermal, dynamic pressure, normal acceleration, and equilibrium glide constraints. The lateral motion is determined through a bank reversal chosen to minimize the final crossrange error. An iteration is used to improve the flight path 
length and curvature estimates. A feedback linearization control tracks the reference drag and heading profiles.

\section{TEST CASES AND TEST CRITERIA}

For the second phase of tests, we included many of the first set of tests again, since the methods did not in most cases perform satisfactorily. We also added tests for various failure and mismodeling cases that seemed appropriate. The test environment was a newer version of MAVERIC that models the X-33 vehicle in more detail and automates the required test processes. A list of the test cases follows in Table 1. Table 2 shows the motivation for each set of tests. Table 3 lists the dispersions modeled for the Monte Carlo runs.

\section{Table 1. Entry Guidance Test Series ${ }^{a}$}

\begin{tabular}{|c|c|c|}
\hline Test Number \& Description & DOF & \# Runs \\
\hline 1) Mich10a1 & 6 & $\begin{array}{c}100 \\
M C D\end{array}$ \\
\hline 2) Mich10a1, February environment, different random seed & 6 & $\begin{array}{c}200 \\
\mathrm{MCD}\end{array}$ \\
\hline 3) Mich10d1 & 6 & $\begin{array}{c}100 \\
\mathrm{MCD}\end{array}$ \\
\hline 4) Mich 10d1, August environment, different random seed & 6 & $\begin{array}{c}200 \\
\mathrm{MCD}\end{array}$ \\
\hline 5) Mich10a1, PPO time 50 sec (early abort to Michael) & 3 & $\begin{array}{c}100 \\
\mathrm{MCD}\end{array}$ \\
\hline 6) Mich10a1, PPO time $60 \mathrm{sec}$ & 3 & $\begin{array}{c}100 \\
\mathrm{MCD}\end{array}$ \\
\hline 7) Mich10a1, PPO time $112 \mathrm{sec}$ & 3 & $\begin{array}{c}100 \\
\mathrm{MCD}\end{array}$ \\
\hline 8) Mich10a1, PPO time $40 \mathrm{sec}$ (early abort to Ibex), different random seed & 3 & $\begin{array}{c}200 \\
\mathrm{MCD}\end{array}$ \\
\hline 9) Mich10d1, PPO time $38 \mathrm{sec}$ (early abort to Ibex), different random seed & 3 & 200 \\
\hline
\end{tabular}


10) Mich10a1, +4 sigma thrust dispersion from ascent

11) Mich10a1, +6 sigma thrust dispersion from ascent

12) Mich10al, -12 sigma thrust dispersion from ascent

13) $51.6 \mathrm{deg}$. ISS orbit entry, low crossrange, high peak heat rate limit, input profile to guidance is from this trajectory's design.

14) $51.6 \mathrm{deg}$. ISS orbit entry, high right crossrange, high peak heat rate limit, input profile from 13.

15) 51.6 deg. ISS orbit entry, high left crossrange, high peak heat rate limit, input profile from 13.

16) $51.6 \mathrm{deg}$. ISS orbit entry, low crossrange, low peak heat rate limit, input profile from this trajectory's design.

17) 51.6 deg. ISS orbit entry, high right crossrange, low peak heat rate limit, input profile from 16.

18) $51.6 \mathrm{deg}$. ISS orbit entry, high left crossrange, low peak heat rate limit, inpu profile from 16.

19) 28.5 deg. LEO orbit entry, low crossrange, low peak heat rate limit, input profile from 16.

20) $28.5 \mathrm{deg}$. LEO orbit entry, high right crossrange, low peak heat rate limit, input profile from 16.

21) $28.5 \mathrm{deg}$. LEO orbit entry, high left crossrange, low peak heat rate limit, input profile from 16.

22) Mich10a1, aerosurface failure result: angle of attack limited to 5 deg. less than nominal entry value.

23) Mich10a1, aerosurface failure result: angle of attack and bank rates limited to 2 deg./sec. maximum.

24) Mich10d1, aerosurface failure: angle of attack limited to $5 \mathrm{deg}$. less than nominal entry value.

25) Mich10d1, aerosurface failure: angle of attack limited to $5 \mathrm{deg}$. less than nominal entry value, and angle of attack and bank rates limited to $2 \mathrm{deg} . / \mathrm{sec}$. maximum

26) Mich 10a1, unknown to guidance, first flight aerodynamics mis-modeling: aerodynamic lift coefficient $20 \%$ less than vehicle database model.

27) Mich10a1, unknown to guidance, first flight aerodynamics mis-modeling: aerodynamic lift coefficient $20 \%$ more than vehicle database model.

28) Mich10al, unknown to guidance, first flight aerodynamics mis-modeling: aerodynamic lift coefficient $20 \%$ less and aerodynamic drag is $20 \%$ more than vehicle database model.

${ }^{\text {a}}$ DOF: degrees of freedom; MCD: Monte Carlo dispersions; PPO: power pack out (engine failure, time of failure indicated); Michael (nominal) and lbex (low energy) are X-33 landing sites; Mich10a1 and 10d1 are different X-33 missions (10d1 is a higher-energy flight); "seed" indicates whether a new random number was used to start certain test cases. All environments 
are for the month of April unless noted. ISS is International Space Station; LEO is low Earth orbit.

\section{Table 2. Motivation for the Tests}

\begin{tabular}{ll} 
Tests & Motivation \\
\hline $1-4$ & $\begin{array}{l}\text { Nominal X-33 missions with dispersions; robustness to dispersions } \\
\text { Engine failures; robustness to large off-energy cases and alternate landing } \\
\text { sites }\end{array}$ \\
$10-12$ & $\begin{array}{l}\text { Large thrust dispersions; ability to maximize probability of successful } \\
\text { landing }\end{array}$ \\
$13-21$ & $\begin{array}{l}\text { Entry from orbit; ability to adapt to different heating requirements and } \\
\text { crossrange requirements with dispersions. }\end{array}$ \\
$22-25$ & $\begin{array}{l}\text { Effects from failures causing a change in maneuverability } \\
\text { Mis-modeling of aerodynamics on first flight }\end{array}$
\end{tabular}

\section{Table 3. Dispersions}

The dispersion category is listed in bold. Dispersed parameters for that category appear after the category in the same row and in subsequent rows until a new category is listed. Aero moment coefficients, hinge moment coefficients, moments of inertia, RCS thrusters, main engine moments, slosh, and aerosurface actuators were dispersed for 6DOF runs only (tests 1-4). Ascent parameters are not dispersed for tests 13-21.

\begin{tabular}{|l|l|l|l|}
\hline $\begin{array}{l}\text { Aerodynamic } \\
\text { (function of Mach, } \\
\text { angle of attack) }\end{array}$ & $\begin{array}{l}\text { Lift, drag, pitch } \\
\text { moment }\end{array}$ & $\begin{array}{l}\text { Body flap pitch } \\
\text { moment, elevon } \\
\text { pitch moment }\end{array}$ & $\begin{array}{l}\text { Pitch moment due to } \\
\text { pitch rate, side force } \\
\text { due to sideslip }\end{array}$ \\
\hline $\begin{array}{l}\text { Roll moment due to } \\
\text { sideslip }\end{array}$ & $\begin{array}{l}\text { Yaw moment due to } \\
\text { sideslip }\end{array}$ & $\begin{array}{l}\text { Side force due to } \\
\text { body flap }\end{array}$ & $\begin{array}{l}\text { Roll moment due to } \\
\text { body flap }\end{array}$ \\
\hline $\begin{array}{l}\text { Yaw moment due to } \\
\text { body flap }\end{array}$ & $\begin{array}{l}\text { Side force due to } \\
\text { elevon }\end{array}$ & $\begin{array}{l}\text { Roll moment due to } \\
\text { elevon }\end{array}$ & $\begin{array}{l}\text { Yaw moment due to } \\
\text { elevon }\end{array}$ \\
\hline
\end{tabular}




\begin{tabular}{|c|c|c|c|}
\hline $\begin{array}{l}\text { Side force due to } \\
\text { rudder }\end{array}$ & $\begin{array}{l}\text { Roll moment due to } \\
\text { rudder }\end{array}$ & $\begin{array}{l}\text { Yaw moment due to } \\
\text { rudder }\end{array}$ & $\begin{array}{l}\text { Roll moment due to } \\
\text { roll rate }\end{array}$ \\
\hline $\begin{array}{l}\text { Roll moment due to } \\
\text { yaw rate }\end{array}$ & $\begin{array}{l}\text { Yaw moment due to } \\
\text { roll rate }\end{array}$ & $\begin{array}{l}\text { Yaw moment due to } \\
\text { yaw rate }\end{array}$ & Atmosphere \\
\hline $\begin{array}{l}\text { Global Reference } \\
\text { Atmosphere Model } \\
\text { (GRAM 99); } \\
\text { random correlated } \\
\text { densities and winds }\end{array}$ & $\begin{array}{l}\text { Hinge Moment } \\
\text { Coefficients } \\
\text { (function of Mach, } \\
\text { angle of attack) }\end{array}$ & $\begin{array}{l}\text { Body flap, rudder, } \\
\text { inboard elevon, } \\
\text { outboard elevon }\end{array}$ & $\begin{array}{l}\text { RCS interference } \\
\text { effects, each } \\
\text { thruster (different } \\
\text { depending on } \\
\text { thruster location) }\end{array}$ \\
\hline $\begin{array}{l}\text { Normal force, side } \\
\text { force, pitch } \\
\text { moment, yaw } \\
\text { moment, roll } \\
\text { moment }\end{array}$ & Mass Properties & $\begin{array}{l}\text { Inert mass, center of } \\
\text { gravity, moments of } \\
\text { inertia }\end{array}$ & $\begin{array}{l}\text { Loaded liquid } \\
\text { oxygen, loaded } \\
\text { liquid hydrogen, } \\
\text { propellant residuals }\end{array}$ \\
\hline $\begin{array}{l}\text { Propellant } \\
\text { Utilization System } \\
\text { liquid oxygen } \\
\text { measurement error }\end{array}$ & $\begin{array}{l}\text { Propellant } \\
\text { Utilization System } \\
\text { liquid hydrogen } \\
\text { measurement error }\end{array}$ & $\begin{array}{l}\text { Navigation } \\
\text { (function of flight } \\
\text { phase) }\end{array}$ & $\begin{array}{l}\text { Position bias, } \\
\text { velocity bias, } \\
\text { acceleration bias }\end{array}$ \\
\hline $\begin{array}{l}\text { Angular rate bias, } \\
\text { Attitude error bias, } \\
\text { Heading error bias }\end{array}$ & $\begin{array}{l}\text { RCS thrusters, } \\
\text { each thruster }\end{array}$ & $\begin{array}{l}\text { Thrust, mixture } \\
\text { ratio, specific } \\
\text { impulse, propellant } \\
\text { load }\end{array}$ & Thruster alignment \\
\hline Main engine & $\begin{array}{l}\text { Force from thrust in } \\
\text { each direction } \\
\text { (function of } \\
\text { altitude) }\end{array}$ & $\begin{array}{l}\text { Aero moment from } \\
\text { thrust about each } \\
\text { axis (function of } \\
\text { altitude) }\end{array}$ & $\begin{array}{l}\text { Fuel flow rate, } \\
\text { oxidizer flow rate, } \\
\text { mixture ratio }\end{array}$ \\
\hline $\begin{array}{l}\text { Specific impulse } \\
\text { (function of } \\
\text { altitude), engine } \\
\text { alignment }\end{array}$ & $\begin{array}{l}\text { Slosh: Slosh mass, } \\
\text { mass location, } \\
\text { frequency, damping }\end{array}$ & $\begin{array}{l}\text { Aerosurface } \\
\text { actuators, each } \\
\text { surface, each } \\
\text { sensor } \\
\end{array}$ & $\begin{array}{l}\text { Position sensor gain } \\
\text { and bias }\end{array}$ \\
\hline $\begin{array}{l}\text { Thermal indicators } \\
\text { (each body point) }\end{array}$ & $\begin{array}{l}\text { Laminar versus } \\
\text { turbulent flow }\end{array}$ & $\begin{array}{l}\text { Engine Plume } \\
\text { Effects (function of } \\
\text { Mach) }\end{array}$ & $\begin{array}{l}\text { Lift, drag, pitch } \\
\text { moment, Roll } \\
\text { moment, yaw } \\
\text { moment, side force }\end{array}$ \\
\hline
\end{tabular}

\section{AUTOMATED SCORING}

The Phase 1 test evaluation involved a number of guidance and control experts reviewing the results (both graphical and numerical) and determining how well the method flew the vehicle. 
This approach worked, but had two drawbacks: 1) It requires a large amount of engineer time for evaluation of many parameters on many tests for multiple algorithms, and 2) the final evaluation has some subjectivity in it (and could potentially result in uneven evaluation). There was a benefit to this method, however. In evaluating the methods, it became clear to the evaluators what parameters were important to them and what values of these parameters were acceptable. The result was the ability to automate the scoring process for the Phase 2 tests.

Tests are numerically scored, and then each test is weighted, with the scores added, so that the algorithms have a final numerical score. Normalization results in a perfect score being given a value of 1.0. For each parameter to be tested, there is a weight, and these multiply that parameter's score and add into the total. Single tests (not Monte Carlo dispersions) are scored as in this example:

Normal acceleration: $0-3.5 \mathrm{~g}, 1.0-2.5 \mathrm{~g}$ means the score is $\mathbf{1 . 0}$ for normal acceleration magnitudes below $2.5,0.0$ for values above 3.5 , and linearly varying in between the two limit values. The parameter score is multiplied by the weight for that parameter (normal acceleration) and added into the total score for that test.

For Monte Carlo dispersion tests, the overall score is the average of the individual scores. A final criteria used for the tests concerns accuracy in reaching the TAEM targets. If the range, altitude, and heading angles are not sufficiently controlled in order to be able to land successfully, the test was considered a failure (score of 0 ) even if other criteria were met. Typical values used for the required accuracy at hitting the TAEM condition were $+/-12.96 \mathrm{~km}$ 
$(7 \mathrm{~nm}), 2.1336 \mathrm{~km}(7000 \mathrm{ft})$, and $10 \mathrm{deg}$, respectively. If more than $10 \%$ of Monte Carlo cases fail to meet these TAEM conditions, then the entire Monte Carlo run is given a score of 0.0 . Exceptions to this last criterion were tests 5 and 8 . The $90 \%$ success criteria resulted in all algorithms failing these two tests. By removing the criteria, it became possible to see the relative scores of the various algorithms and thus to have a means for comparing them.

Table 4 lists the criteria compared for each of the various tests.

\section{RESULTS}

Results of the tests are shown in the figures below. These tests have been performed a number of times, with the algorithm designers given a chance to correct problems in their method's performance during the process. The baseline X-33 entry guidance (Shuttle-like) is shown for comparison for tests where it is set up to fly the vehicle.

Figure 1 shows the performance for the entry guidance test cases. A score of 0.0 means that the algorithm failed the test. If more than one algorithm failed the test, a slightly negative score is used so that the reader is able to see the scores in the figure. The X-33 baseline guidance is used for tests 1-12 only. It is clear that it performs quite poorly as compared to the other algorithms. The reason for this is clearly visible in Figure 2, which shows results from Test Case 1. The nominal TAEM interface altitude and range are $29.344 \mathrm{~km}(96,274 \mathrm{ft})$ and $55.56 \mathrm{~km}(30 \mathrm{~nm})$ respectively. Although the baseline guidance has values generally clustered in this vicinity, the spread is significantly greater than the LQR TAEM spread, which is very tight around the nominal values. Four of the 100 cases for the baseline are off the graph and others would not be 
land-able. The particular failed criterion in this case is that at least $90 \%$ of cases must be within $12.96 \mathrm{~km}(7 \mathrm{~nm})$ of the desired TAEM range condition. Although this baseline algorithm would be completely acceptable for flying a typical Shuttle entry profile that has a long time available for removing dispersions as well as a benignly-designed trajectory, the guidance for this $\mathrm{X}-33$ sub-orbital case was required to remove ascent dispersions on a relatively sporty entry profile in a much shorter period of time. This may be necessary in some downrange abort scenarios for an orbital vehicle.

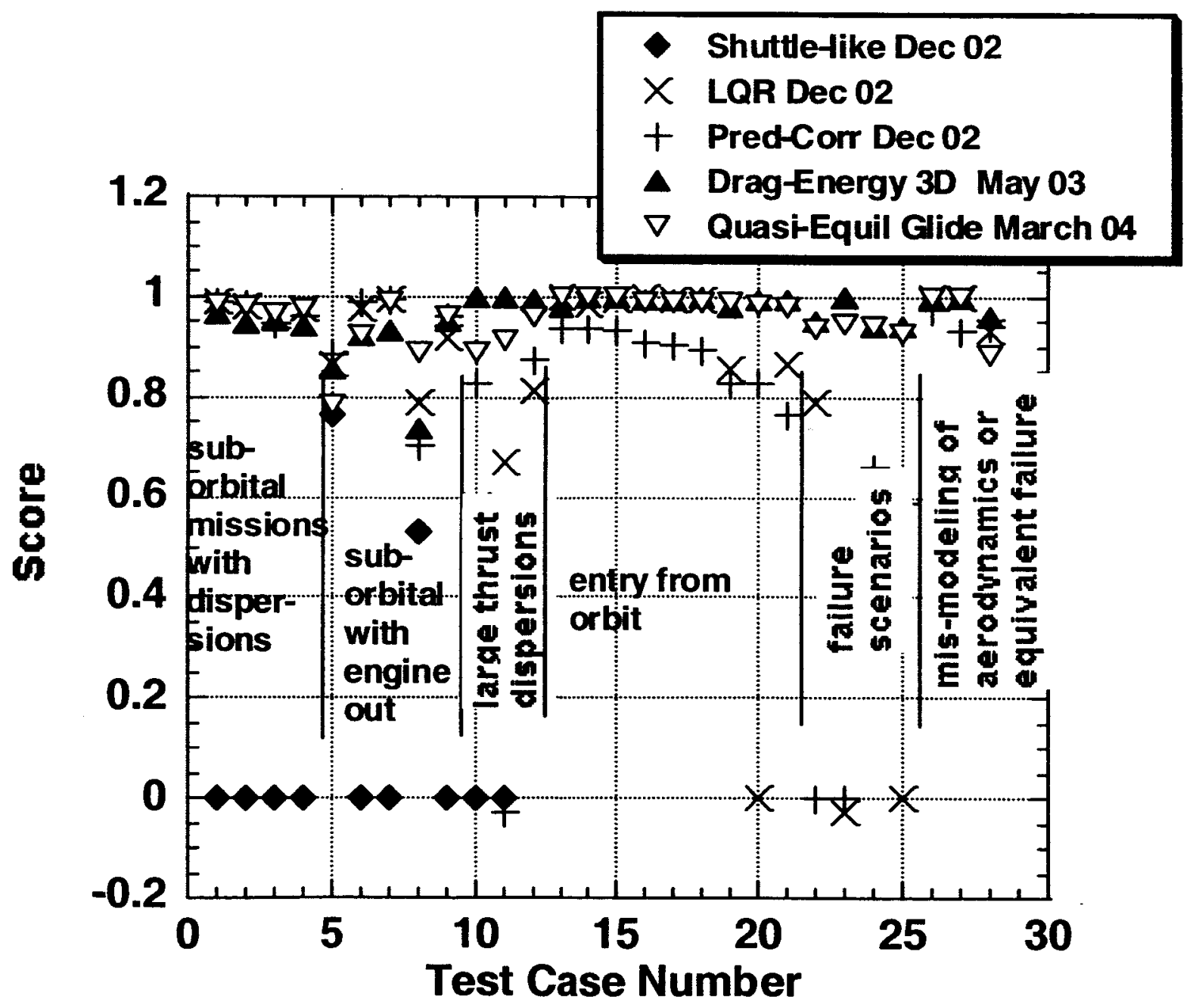

Figure 1. Entry Guidance Test Scores 


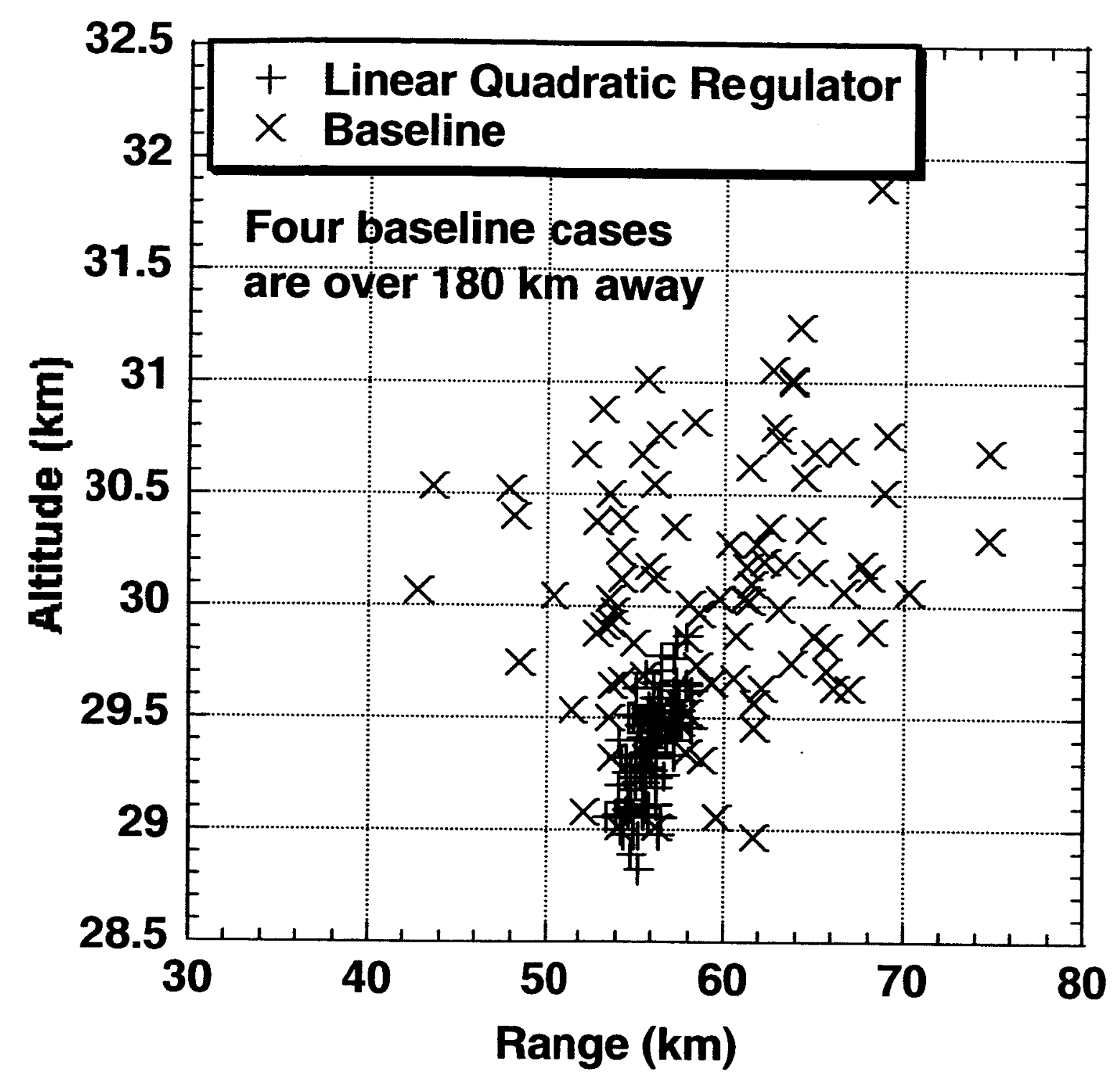

Figure 2. Altitude vs Range Comparison for Entry Guidance (Test Case 1)

The LQR algorithm scores fairly well across the board, although it fails some of the more difficult cases, probably due to the fact that it does not have a trajectory profile tailored more to that case. Test case 20 is a high crossrange case that LQR fails because it does not have a 
trajectory profile tailored to high crossrange. $L Q R$ would be a good choice for a simple, robust guidance that does not involve on-board trajectory design.

The predictor-corrector (Eguide) method performs well, although it has some problems. Its capability to design smooth new profiles, combined with a robust guidance that includes the LQR after the high heating region is passed, leads to robust performance. It fails some of the toughest tests. The designer of this algorithm realized that further improvements would possibly have removed the failures. However, he decided not to continue working on the algorithm 


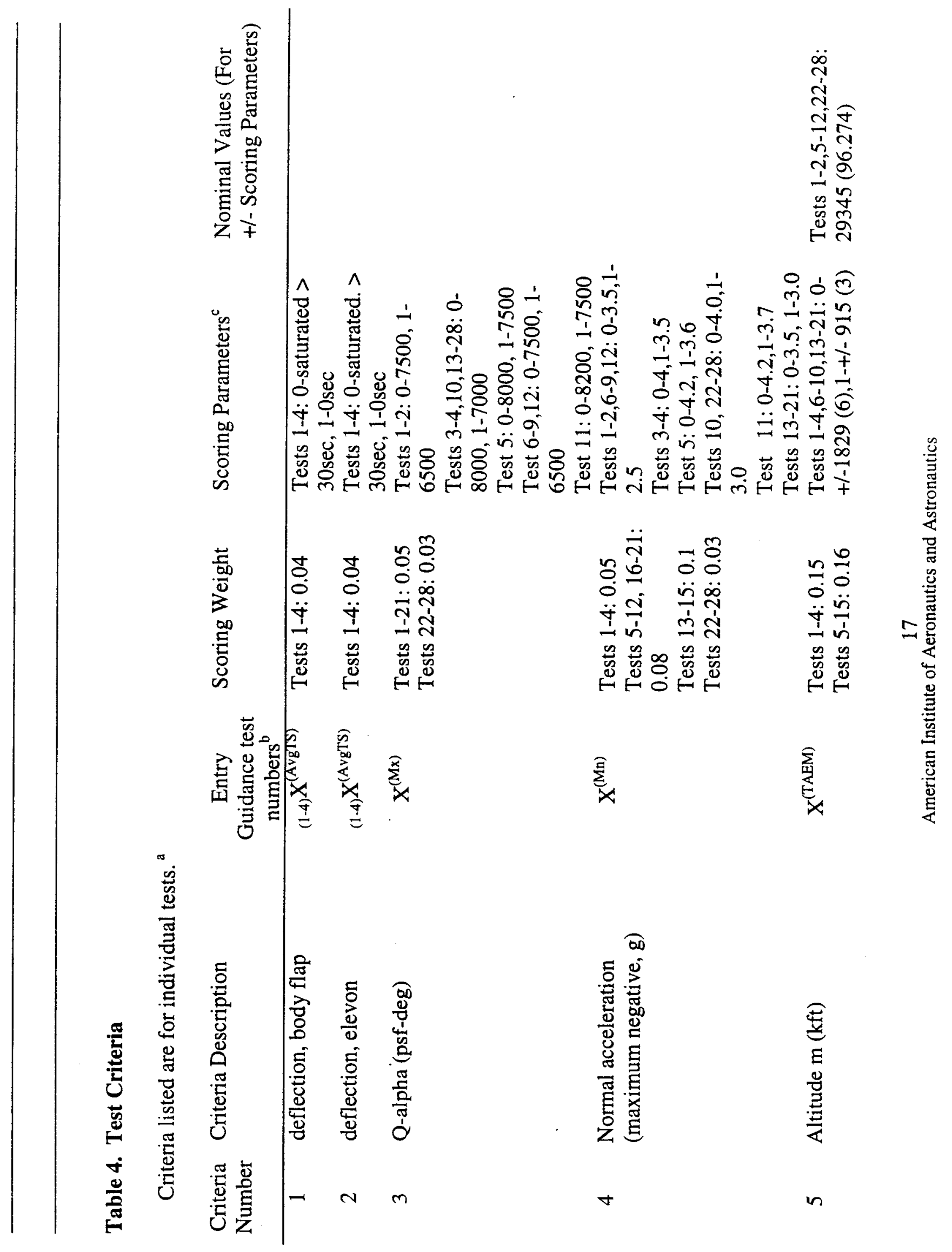




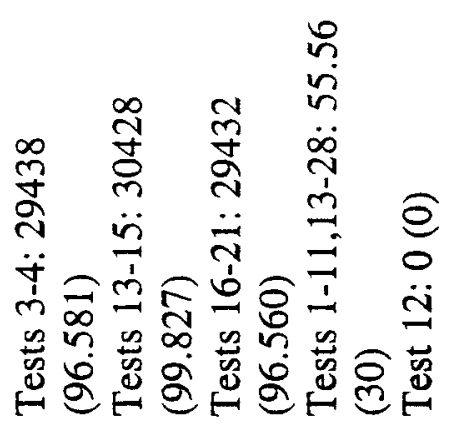

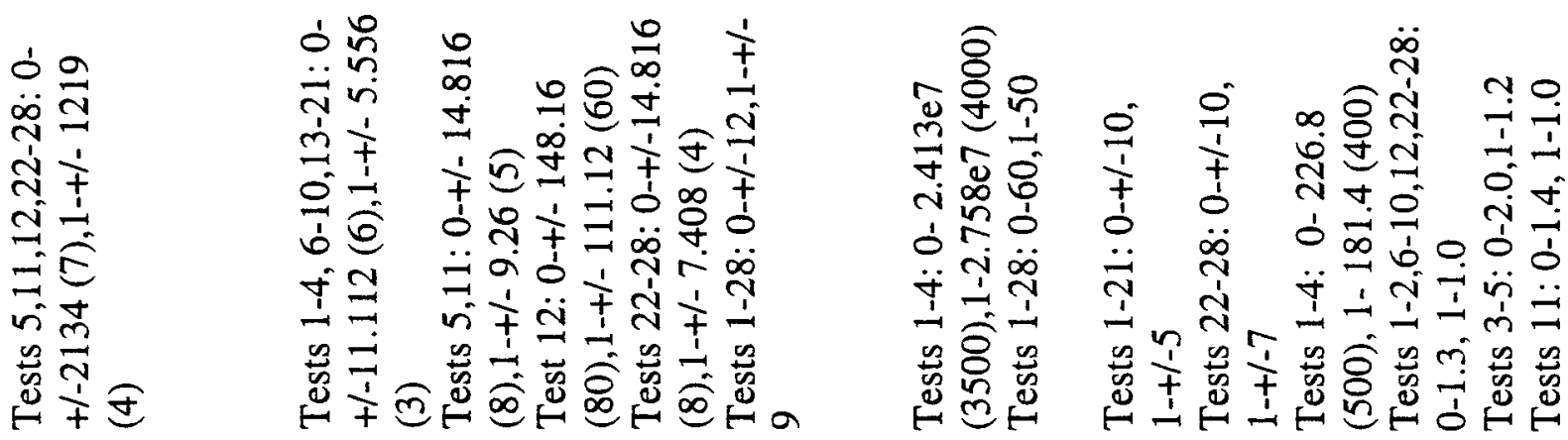

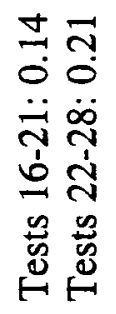

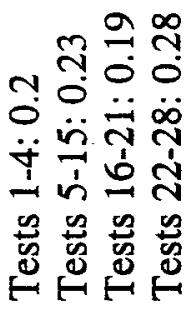

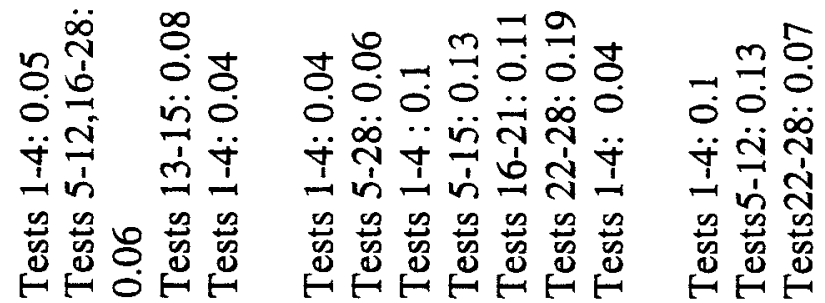

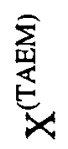

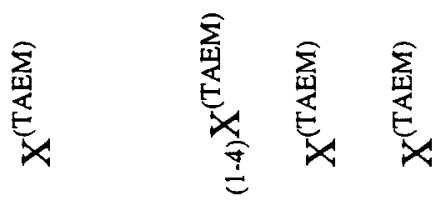

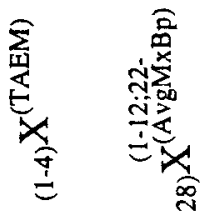

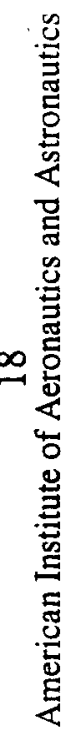

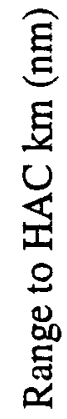

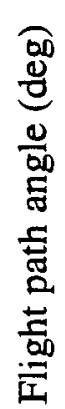

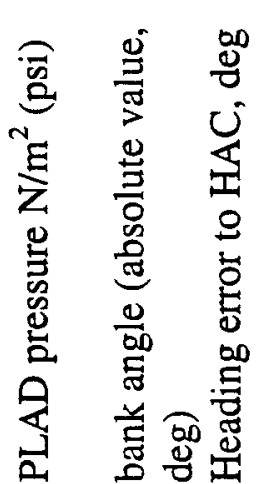

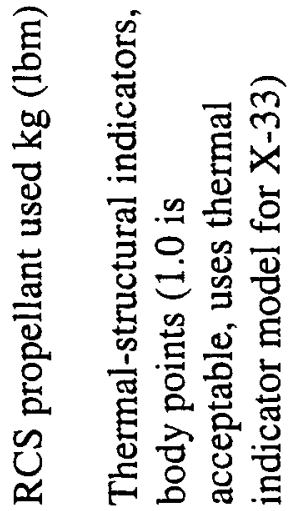

6

$n$

$\infty$ a 음

$\exists \quad I$ 


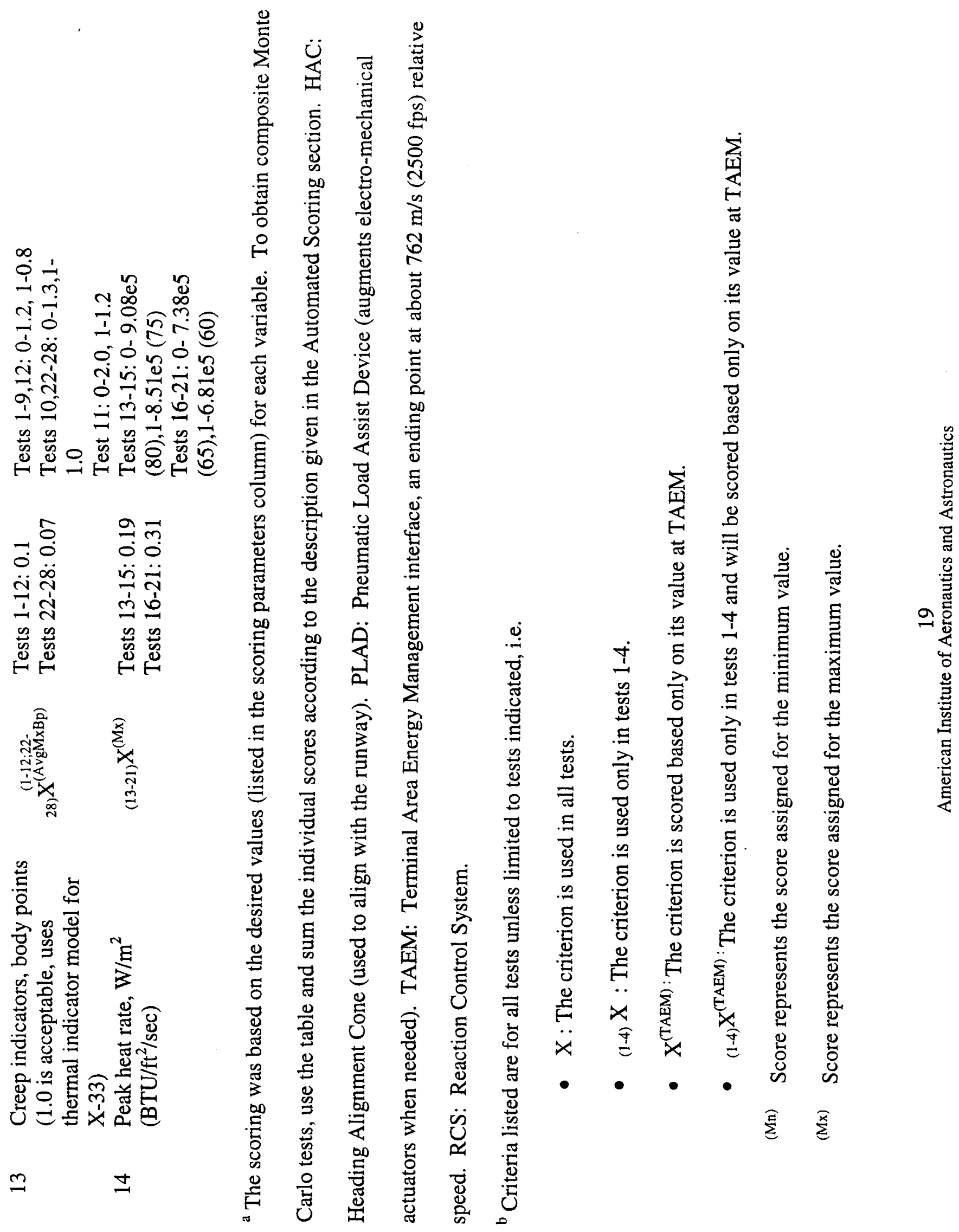




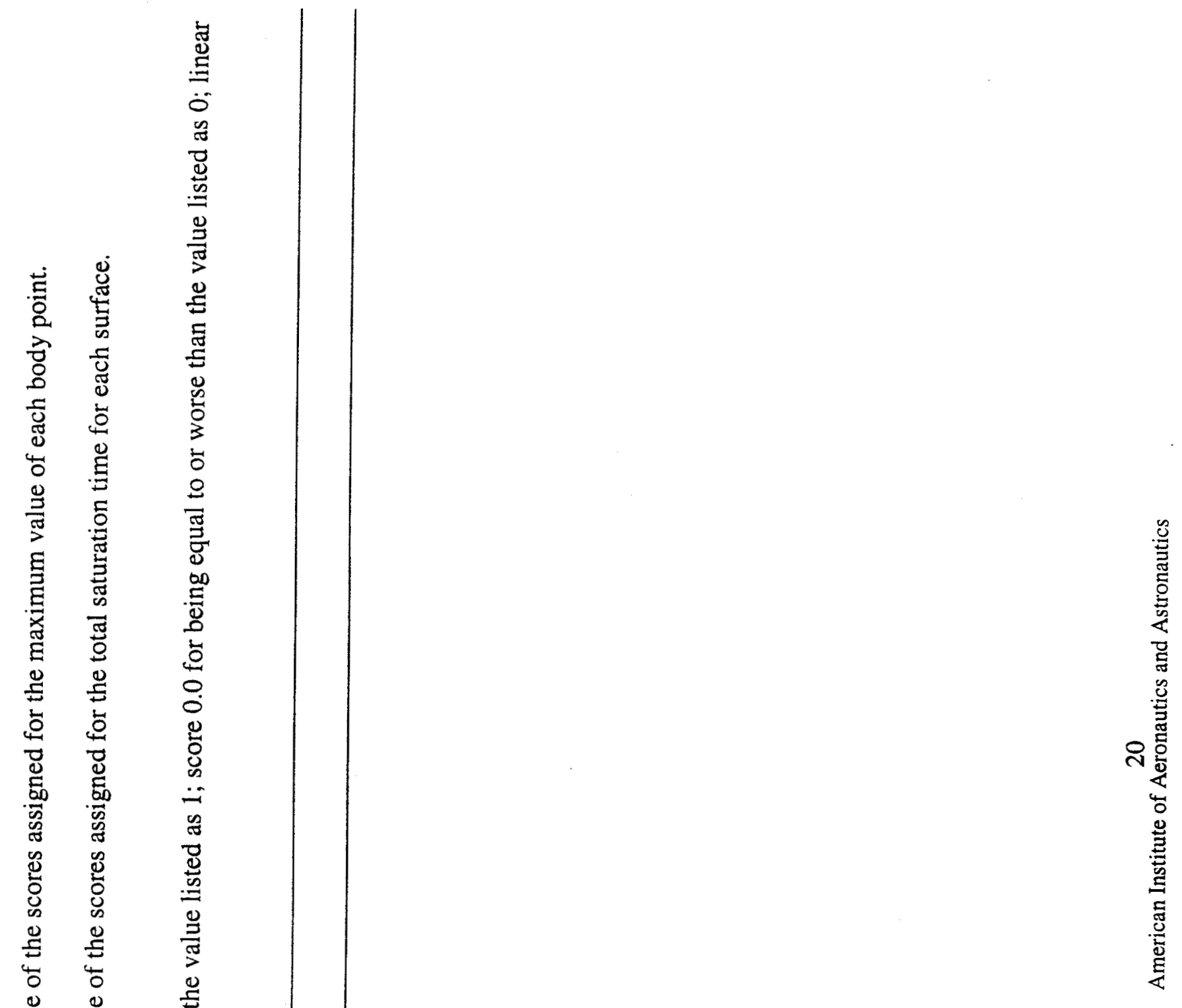


after seeing success in the other algorithms. Further work may have brought the performance of this approach up to near the others, but would have probably not yielded equal or greater performance.

The quasi-equilibrium glide approach and the EAGLE algorithm both performed extremely well. Both approaches passed all the tests and performed well on all tests. The total scores for the various algorithms, as of the most recent testing, are:

Drag-Energy 3D

Quasi-Equilibrium Glide

Linear Quadratic Regulator

Predictor-Corrector

Shuttle-like

8.4 (out of a possible 50 due to being tested against tests $1-12$ only)

Note that the drag-energy 3D algorithm was submitted separately for the different X-33 missions (10al and 10d1), whereas the quasi-equilibrium glide testing is for a single algorithm.

Ultimately a single algorithm is necessary that is flexible enough to fly the different missions without modification.

The criteria graph (Fig. 3) shows the performance on the various criteria for each algorithm. The criteria are listed in Table 4. The performance is shown only for those tests that did not fail (did not score a zero on the test cases graph). This way, the reader will see information on how the 
method performed for the various criteria. The number of successful tests for each algorithm can be determined from the test cases graph. Since the baseline passed only three tests, its criteria numbers are not meaningful and are left out of the figure.

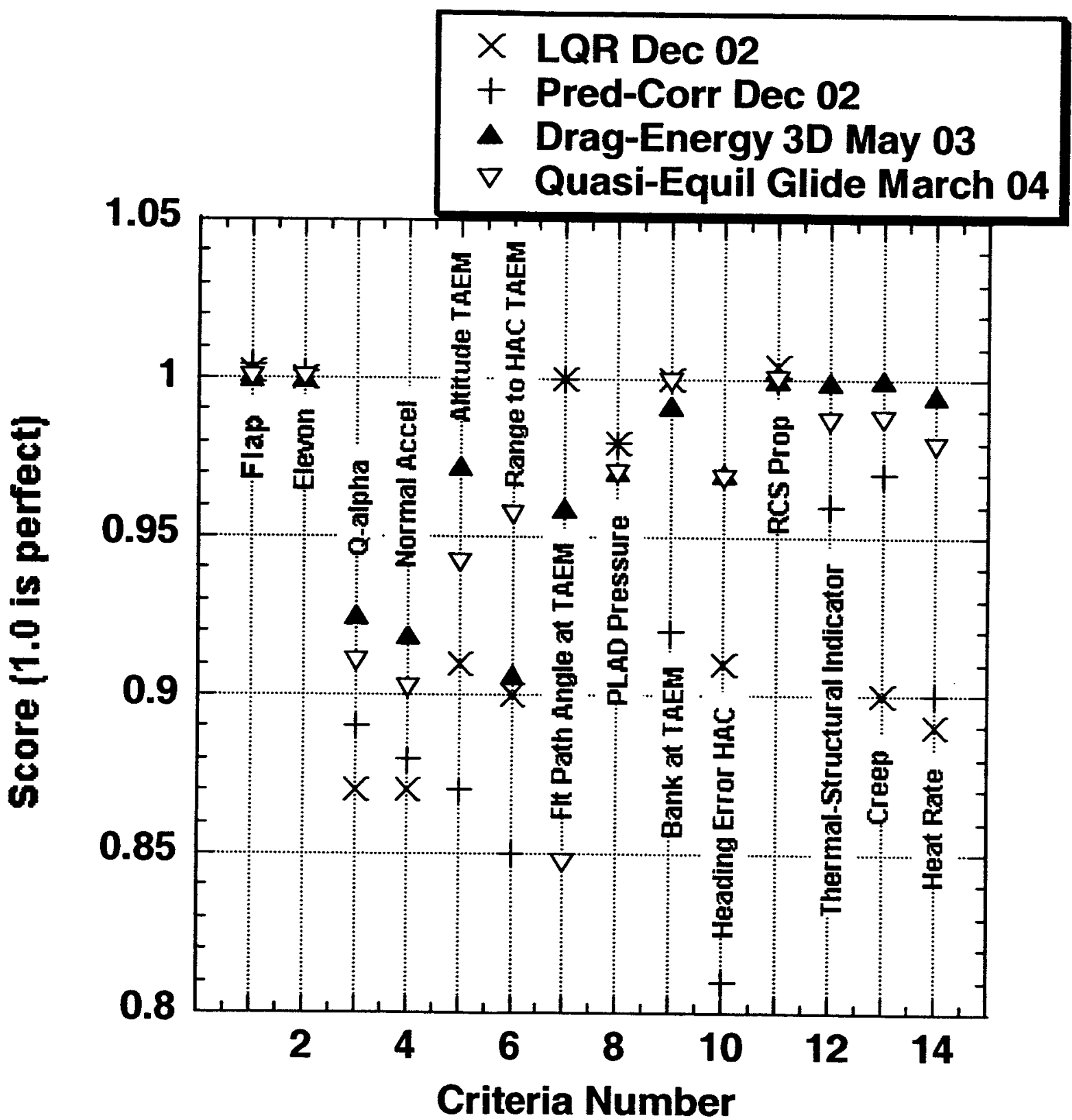

Figure 3. Criteria Scores 
All of the new algorithms performed fairly well against the various criteria. There are some differences where some of the approaches are stronger than others.

\section{COMPUTATIONAL INTENSITY}

The speed of computation of the various algorithms was measured in order to verify that they could be flown and used in real time. The following table shows the computer time spent on the first call to entry guidance for the Michael 10al trajectory:

CPU Time Spent on First Guidance Call

$\begin{array}{ll}\text { Algorithm } & \text { CPU time (sec) } \\ \text { Baseline } & 0.000314337 \\ \text { Linear Quadratic Regulator } & 1.22419 \mathrm{E}-05 \\ \text { Predictor Corrector } & 0.259041114 \\ \text { Pseudo-Equilibrium Glide } & 0.078994312 \\ \text { Drag-Energy 3D } & 0.031893107\end{array}$

The computer speed is $525 \times 10^{6}$ cycles per second. All subsequent calls to guidance used less CPU time than the first call. The predictor corrector, pseudo-equilibrium glide, and drag-energy 3D approaches used more time than the baseline and LQR methods because they calculated a new trajectory prior to flying it. In most cases, subsequent calls to guidance use far less CPU time than the first call. From the table, it is apparent that it should be possible to use any of these algorithms for real-time entry guidance. Trajectory generation takes more time, but should fit 
within computing capabilities of future on-board computers. The initial trajectory generation can be performed over a period of time if necessary, during the coast before entry guidance begins its closed-loop operation. The calls for guidance only and not trajectory generation should not tax the computer significantly. If trajectory generation is necessary after entry starts, it should be able to accomplish it within the computing capabilities of the on-board computer, in a few guidance cycles if not in one (assuming a typical guidance cycle of one second). One issue is that the time taken to generate a trajectory, with iterations involved, can be variable. The times above are not necessarily the maximum that would ever be seen. This would need to be taken into account in developing the real-time system.

\section{CONCLUSIONS}

This paper gives the results from testing entry guidance methods for application to future entering space vehicles. The methods were tested in high-fidelity simulation to determine their performance with respect to nominal missions, engine-out situations, dispersions, various failures, and vehicle mis-modeling. All the new approaches significantly outperformed the Shuttle-based entry guidance design. The quasi-equilibrium glide approach and the drag-energy 3D method (EAGLE) both performed extremely well. We believe they are now proven to the extent that they can be expected to work well on a future vehicle application. The LQR approach, while having more difficulty with some of the tests as compared to the two top performers, is simpler computationally and would represent a good choice for a lower-risk approach. The quasi-equilibrium glide and LQR approaches have since been used in simulation for potential new space vehicles (the X-37 Orbital Vehicle and the Orbital Space Plane). They 
apply to a wide range of vehicle types and have performed well for vehicles with low lift-to-drag ratios in addition to their proven performance for high lift-to-drag ratios. Expected flight processor capabilities should be able to handle the computational needs of the various algorithms tested.

As of this writing, the EAGLE method is not a single algorithm, but has been delivered separately for different test cases. It still needs to be modified so that it will be able to fly modified missions equally well without changing the algorithm.

For future differentiation between the various approaches, an option would be to define a couple of additional tests to hopefully separate the two top performing algorithms. The tests might include running the algorithms for some scenarios that were not available to the designers, to find out how robust they are to unforeseen scenarios.

Follow-on work is planned in all the other areas of advanced guidance and control, which are not as far developed as the entry guidance. Although work is progressing on all fronts, much work remains to be done. Each of the best algorithm approaches should then be integrated into an overall advanced guidance and control architecture. Making this complete architecture work together well is not a simple task in itself, since flying some difficult failure cases may take a combination of the efforts of multiple individual algorithms. This architecture would be shown to meet the safety, reliability, and cost objectives. 
Integration into a complete architecture requires more than simply connecting the algorithms and making sure they work together. An example is a study where an elevon failure during entry meant that the vehicle could not maintain the same angle of attack profile due to no longer having sufficient control authority. The RCS jets were not powerful enough to compensate for the failure, and the RCS fuel used would be excessive. However, by flying at a lower angle of attack, using RCS to help compensate for the loss of control, and redesigning the trajectory with the new angle of attack profile, it is possible to save the mission. Examples like this one show how these new methods can be used to advantage.

There are a couple of issues that can be identified with the new entry guidance approaches. First, because the trajectory design process involves iteration, it is likely to be a process that takes a variable length of time. This issue will have an impact on the real-time software design. Secondly, there is the issue of verifying that the new methods will never cause a vehicle to fail due to a failure to converge or some other reason with similar impact. Verification and reduction of risk could include showing that the new method flies all the expected scenarios (different missions and dispersions) successfully, as well as expands the envelope to include successfully flying cases that would have previously failed. To further reduce risk, a nominal trajectory could be stored and used as long as conditions do not require a new trajectory. With that approach, the new method would only add to safety because it would only compute new trajectories in cases that would have failed (or would at least be near failure) previously. Software would need to be added to make the decision that a new trajectory is necessary.

\section{REFERENCES}


1. Hanson, J., "A Plan for Advanced Guidance and Control Technology for $2^{\text {nd }}$ Generation Reusable Launch Vehicles," AIAA paper 2002-4557, Aug. 2002.

2. Hanson, J., "New Guidance for New Launchers," Aerospace America, March 2003, pp. 3641.

3. Hanson, J., "Advanced Guidance and Control Project for Reusable Launch Vehicles," AIAA paper 2000-3957, Aug. 2000.

4. Hanson, J., Jones, R., and Krupp, D., “Advanced Guidance and Control Methods for Reusable Launch Vehicles: Test Results," AIAA paper 2002-4561, Aug. 2002.

5. Hanson, J.M., Coughlin, D.J., Dukeman, G.A., Mulqueen, J.A., and McCarter, J.W., “Ascent, Transition, Entry, and Abort Guidance Algorithm Design for the X-33 Vehicle," AIAA paper 98-4409, Aug. 1998.

6. Dukeman, G.A., "Profile-Following Entry Guidance Using Linear Quadratic Regulator Theory," AIAA paper 2002-4457, Aug. 2002.

7. Zimmerman, C., Dukeman, G., and Hanson, J., "An Automated Method to Compute Orbital Re-entry Trajectories with Heating Constraints," AIAA paper 2002-4454, Aug. 2002.

8. Shen, Z., and Lu, P., “On-Board Generation of Three-Dimensional Constrained Entry Trajectories," Journal of Guidance, Control, and Dynamics, Vol. 26, No. 1, 2003, pp. 111121.

9. Lu, P., "Regulation about Time-Varying Trajectories: Precision Entry Guidance Illustrated", Journal of Guidance, Control, and Dynamics, Vol. 22, No. 6, 1999, pp. 784-790.

10. Chen, D.T., Saraf, A., Leavitt, J.A., and Mease, K.D., "Performance of Evolved Acceleration Guidance Logic for Entry (EAGLE)," AIAA paper 2002-4456, Aug. 2002. 
11. da Costa, O., and Sachs, G., "Effects of Controls Degradation on Flight Mission of Reentry Vehicle," AIAA paper 2002-4848, Aug. 2002.

Biographies

Dr. John M. Hanson, NASA Marshall Space Flight Center

Dr. Hanson earned his Ph.D. degree in Aerospace Engineering from the University of Michigan in 1983. Prior to his NASA employment, he worked at the ANSER Corporation, where he studied sensor systems, satellite constellations, and orbital mechanics. Since coming to NASA, he has done research and applied work in trajectory optimization, guidance schemes, and automated rendezvous. He is currently Lead of Marshall Space Flight Center's Trajectory and Guidance Team. He is also the principal investigator for a project titled Integration and Testing of Advanced Guidance and Control Technologies, developing new methods for reusable space vehicles to improve safety and reduce cost.

Mr. Robert E. Jones, Sverdrup Technology

Mr. Jones earned his MSME degree in Mechanical Engineering from the Rose-Hulman Institute of Technology in 1989. Further graduate study in Rotordynamics was done at Texas A\&M University before coming to Sverdrup. Prior to studying engineering, Mr. Jones served as a Non-Commissioned Officer in the USMC and was commissioned in the US Navy. He holds two patents and is published for his work in Bio-Medical Engineering while working at the National 
Institutes of Health. Current work involves Testing of Advanced Guidance and Control Technologies. 